\title{
LXR Activation Down-regulates Lipid Raft Markers FLOT2 and DHHC5 in MCF-7 Breast Cancer Cells
}

\author{
DELPHINE CARBONNELLE ${ }^{1}$, TRANG H. LUU ${ }^{1}$, CHLOE CHAILLOU ${ }^{1}$, \\ JEAN-MICHEL HUVELIN ${ }^{1}$, JEAN-MARIE BARD ${ }^{1,2}$ and HASSAN NAZIH ${ }^{1}$ \\ ${ }^{1}$ Faculty of Pharmacy, EA 2160 MMS - «Institut Universitaire Mer et Littoral», FR3473 CNRS, \\ «Centre de Recherche en Nutrition Humaine Ouest» (CRNH Ouest), UBL Nantes University, Nantes, France; \\ ${ }^{2}$ ICO René Gauducheau, Unicancer, St Herblain, France
}

\begin{abstract}
Background/Aim: Lipid rafts are cholesterolenriched microdomains of the plasma membrane. Recent studies have underlined that their integrity is critical for cancer cell survival. Liver X receptor (LXR) has a central role in cellular cholesterol homeostasis and its stimulation inhibits proliferation of several cancer cell lines. This study investigated whether LXR could modulate lipid rafts integrity and consequently alter proliferation of the MCF-7 breast cancer cell line. Materials and Methods: Effect of LXR agonist T0901317 on integrity of MCF-7 lipid rafts was examined by studying the expression of rafts marker flotillin2 (FLOT2) and DHHC5, which palmitoylates FLOT2, and by studying the expression of phospho-Akt. Results: We demonstrated that LXR stimulation decreases mRNA and protein expression of FLOT2 and DHHC5 in MCF-7 cells. LXR stimulation also reduces Akt phosphorylation and its localization at the plasma membrane. Conclusion: We showed, for the first time, that LXR regulates transcription of specific proteins of lipid rafts in a breast cancer model.
\end{abstract}

Breast cancer is the most common malignancy in women worldwide, accounting for $25 \%$ of the total cancer cases in 2012 and $14 \%$ of the total cancer related deaths (1). A better understanding of the breast cancer cell metabolism and identification of novel key molecules involved in malignant properties are always of great value and could provide new therapeutic targets.

Lipid rafts are sphingolipids and cholesterol-enriched microdomains of the plasma membrane and their integrity

Correspondence to: Hassan Nazih, UBL Nantes University, Faculty of Pharmacy, EA 2160 MMS - Laboratoire de Biochimie, 1 rue Gaston Veil 44068 Nantes, France. Tel: +33 244769044, e-mail: elhassane.nazih@univ-nantes.fr

Key Words: Lipid rafts, MCF-7, LXR, flotillin-2, DHHC5. attested by cholesterol content and the presence of anchor proteins (like Flotillins) is critical for the distribution of raftassociated proteins especially those involved in survival signaling such as PI3K/Akt $(2,3)$. Moreover, the association of these factors with rafts is often related to post-translational activation like their phosphorylation (critical for Akt) on Sacylation. In this regard, recent findings have shown the critical role of palmitoylation cycle for localization of the NRAS and HRAS factors at the plasma membrane (4). Similarly, it seems that in general, proteins with high affinity for rafts are mostly palmitoylated (5), for example Flotillins $(6,7)$. Due to their localization in lipid rafts, Flotillin proteins play important roles in various cell processes such as adhesion, endocytosis, phagocytosis and transduction of cellular signals. In addition, the involvement of Flotillins and especially FLOT2 in carcinogenesis has been recently demonstrated (8). Thus, Flotillins seem to be more than simple markers of lipid rafts and in this field, recent findings have shown that they colocalize with NPC1L1 and ABCG1, two proteins involved in cholesterol homoeostasis, which are regulated transcriptionally by the nuclear transcription factors LXRs (Liver X Receptor) upon binding of certain oxysterols or synthetic ligands such as T0901317 $(9,10)$.

LXR activation induces regulation of target genes many of which are keys regulators of lipogenesesis and cholesterol metabolism (11). Recent studies have reported the antiproliferative effects of synthetic and natural LXR agonists in various types of human cancer cells in vitro and in xenograft models such as prostate $(12-14)$ ovarian $(15,16)$, colon $(17$, $18)$, and breast cancer $(19,20)$. It has also been recently reported that anti-proliferative effects of LXR agonists on breast cancer cells is correlated with enhanced extracellular cholesterol efflux $(21,22)$.

In cancer cells, lipid raft microdomains are often overexpressed and their disorganization can induce apoptosis of tumor cells (23). The efficiency of targeting lipid rafts in mammary tumor cells has been recently shown $(24,25)$. 
Therefore, one could expect that disrupting lipid rafts in cancer cells, by targeting cellular cholesterol homeostasis and/or anchor proteins integrity, should alter the survival pathway activation thus inducing cellular apoptosis. In agreement with this hypothesis, a link between disruption of lipid rafts and pharmacological induction by LXR ligands has been documented by Pommier et al., in a prostate cancer model (14).

The general purpose of this study was to investigate more precisely the effect of an LXR agonist on MCF-7 lipid rafts. We showed that LXR agonist T0901317 induced lipid raft disruption of MCF-7 cells attested by down-regulation of FLOT2 and its membrane associated palmitoylation enzyme, DHHC5, at both mRNA and protein levels. In addition, we showed that disruption of lipid rafts is linked to the antiproliferative effect of T0901317 and the down-regulation of Akt phosphorylation.

\section{Materials and Methods}

Materials. Human breast cancer MCF-7 cells were from the European Collection of Animal Cell Cultures (ECACC, Salisbury, UK). 3-(4,5-Dimethyl-2-thiazolyl)-2,5-diphenyltetrazolium bromide (MTT), T0901317, and other chemicals were purchased from Sigma Aldrich (Saint Quentin Fallavier, France). Primers for qPCR were purchased from Sigma Aldrich. TRIzol reagent for RNA isolation was from Invitrogen (Cergy Pontoise, France). iScript ${ }^{\mathrm{TM}}$ Reverse Transcription Supermix for RT-qPCR and $\mathrm{iQ}^{\mathrm{TM}}$ SYBR Green Supermix were purchased from Bio-Rad (Marnes-la-Coquette, France). Rabbit antibody against FLOT2, DHHC5, Glyceraldehyde3-phosphate dehydrogenase (GADPH) and mouse antibody against $\beta$-Actin were from Sigma Aldrich (Saint Quentin Fallavier, France). Antibodies against phospho-Akt and Total Akt were purchased by Cell Signaling Technology (Ozyme, Saint-Quentin en Yvelines, France). Goat anti-Rabbit IgG(H+L) Secondary Antibody coupled to Alexa Fluor 488 was from Life Technologies (Saint-Aubin, France). The IRDye whole IgG secondary antibodies were from LICOR Biosciences (Bad Homburg, Germany).

Cell culture. MCF-7 cells were cultured at $37^{\circ} \mathrm{C}$ in a humidified incubator with $5 \% \mathrm{CO}_{2}$ in Dulbecco's Modified Eagle's Medium (DMEM), supplemented with $10 \%$ fetal bovine serum (FBS), $1 \%$ glutamine and $1 \%$ penicillin-streptomycin (complete medium). Triton X-100 extraction of lipid rafts.

Extraction of lipid rafts was performed as previously described (26). MCF-7 cells were plated at a density of $1.5 \times 10^{6}$ in a petri dish in $12 \mathrm{~mL}$ culture medium and were allowed to adhere overnight. Then the seeding medium was removed and cells were treated with the LXR agonist (T0901317 at $20 \mu \mathrm{M}$ ), diluted in $0.1 \%$ fatty acidfree BSA-containing medium for $24 \mathrm{~h}$ and $48 \mathrm{~h}$ at $37^{\circ} \mathrm{C}$. After incubation period, cells were harvested and resuspended in $300 \mu \mathrm{l}$

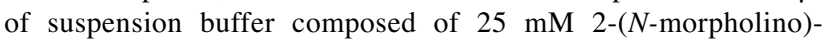
ethanolsulfonic acid (MES) and $150 \mathrm{mM} \mathrm{NaCl}(\mathrm{pH} \mathrm{6.5)}$. An additional $300 \mu \mathrm{L}$ of the same buffer plus $2 \%$ triton $\mathrm{X}-100$ with Halt $^{\text {TM }}$ Protease and Phosphatase Inhibitor Single-Use Cocktail (Life Technologies, Saint-Aubin, France) was added to the cells suspension and incubated for $30 \mathrm{~min}$ on ice. The insoluble lipid raft microdomain fractions were then pelleted by centrifugation at 14000 $\times g$ for $20 \mathrm{~min}$ at $4^{\circ} \mathrm{C}$. The soluble supernatant was removed and designated as non-lipid rafts soluble fraction (CYTOSOL). Afterwards, the lipid raft pellets were resuspended in a new buffer composed of $1 \%$ triton X-100, $10 \mathrm{mM}$ Tris (pH 7.6), $500 \mathrm{mM} \mathrm{NaCl}$, $60 \mathrm{mM} \beta$-octylglucoside and Halt ${ }^{\mathrm{TM}}$ Protease and Phosphatase Inhibitor Single-Use Cocktail and incubated for $30 \mathrm{~min}$ on ice. The solubilized lipid raft fractions (RAFT) were then separated as supernatants by centrifugation at $14,000 \times \mathrm{g}$ for $20 \mathrm{~min}$ at $4^{\circ} \mathrm{C}$. The protein concentration was determined using the BCA Protein Assay method (Sigma Aldrich, Saint Quentin Fallavier, France).

Whole cell lysates extraction. MCF-7 cells were plated at a density of $5 \times 10^{5}$ in a 6 -well plate and were allowed to adhere overnight. Then, the seeding medium was removed and cells were treated with LXR agonist (T0901317 at $20 \mu \mathrm{M}$ ), diluted in $0.1 \%$ BSA-containing medium for $24 \mathrm{~h}$ and $48 \mathrm{~h}$ at $37^{\circ} \mathrm{C}$. Supernatants were then removed and cells were washed with fresh PBS and lysed in $300 \mu \mathrm{l} \mathrm{M-}$ PER $^{\mathrm{TM}}$ Mammalian Protein Extraction Reagent (MPER) (Life Technologies, Saint-Aubin, France), that contained protease and phosphatase inhibitors cocktail. Lysates were centrifuged at $4^{\circ} \mathrm{C}$ for $30 \mathrm{~min}$ at $12,000 \times \mathrm{g}$. The protein concentration was determined using the BCA Protein Assay method.

Western blot analysis. Proteins of Triton X-100 extraction or whole cell lysates were separated with $4-15 \%$ SDS polyacrylamide gel electrophoresis (SDS-PAGE) and were transferred to a nitrocellulose membrane. Membranes were blocked for $1 \mathrm{~h}$ with $5 \%$ milk Trisbuffered saline (TBS)-Tween solution and then incubated overnight at $4^{\circ} \mathrm{C}$ with primary antibodies against human FLOT2 (Sigma Aldrich, Saint Quentin Fallavier, France) or DHHC5 (Sigma Aldrich, Saint Quentin Fallavier, France), GADPDH or $\beta$-Actin. Proteins bands were then detected by incubation with IRDye Whole IgG anti rabbit or anti mouse secondary antibodies and visualized by system Licor Odyssey Scanner. Quantification was made with $\beta$ actin or GAPDH loading control.

Cell viability test. Cells were plated at a density of $10^{4}$ cells per well in a 96-well plate in $200 \mu \mathrm{l}$ of culture medium and allowed to adhere overnight. The seeding medium was then removed and cells were treated with T0901317 at different concentrations diluted in $0.1 \%$ BSA-containing medium for 48,72 or $96 \mathrm{~h}$. For the MTT assay, MTT solution $(50 \mu \mathrm{L}$ of $2.5 \mathrm{mg} / \mathrm{ml})$ was added to each well to get formazan crystals. After $4 \mathrm{~h}$ of incubation, the liquid in the wells was removed and formazan deposit was solubilized in $200 \mu \mathrm{l}$ of DMSO. The absorbance of formazan solution at $570 \mathrm{~nm}$ was measured using SpectraMax 190. Relative cell viability was expressed as a percentage of the control that was not treated with LXR ligand.

Flow cytometry analysis. MCF-7 cells were treated with the LXR agonist in a 6-well plate, as described in the previous section on whole cell lysate extraction. After $48 \mathrm{~h}$, cells were harvested and fixed with $4 \%$ formaldehyde followed by permeabilization with $90 \%$ ice-cold methanol at $4^{\circ} \mathrm{C}$ for $30 \mathrm{~min}$. After washing, cells were stained with anti-phospho Akt (Thr308) rabbit mAb for $1 \mathrm{~h}$, followed by alexa fluor 488 coupled anti-rabbit antibody secondary stain. Analyses were performed on a BD Accuri cytometer (BDAccuri ${ }^{\mathrm{TM}} \mathrm{C} 6$ ).

Immunofluorescence assay. MCF-7 cells, grown on coverslips, untreated or treated with TO901317 at $20 \mu \mathrm{M}$ for $48 \mathrm{~h}$, were fixed with $4 \%$ PAF, blocked and permeabilized simultaneously in $3 \%$ BSA $/ 0.3 \%$ Triton X100 then incubated overnight at $4^{\circ} \mathrm{C}$ with the 
Table I. Primer sequences used in this study.

\begin{tabular}{ll}
\hline Gene name & Sequences (5'-3') \\
\hline $18 S$ & F-GATGCGGCGGCGTTATTCC \\
& R-CTCCTGGTGGTGCCCTTCC \\
FLOT2 & F-CAAGATTGCTGACTCTAAGC \\
& R-GCACAACCTCAATCTCAATC \\
DHHC5 & F-AGGAATTTGATCATCACTGG \\
& R-CTGAGAGTTCCTCTATGTGG \\
\hline
\end{tabular}

primary anti-phospho Akt (Thr308) rabbit mAb followed by staining with alexa-fluor- 488 coupled anti-rabbit secondary antibody. The nuclei were stained with 4,6-diamido-2-phenylindole (DAPI) for 5 min. Cells were observed using an Axio Imager M2m microscope (Carl Zeiss, Jena, Germany), equipped with an AxioCam 503 mono at $40 \times$ magnification. Negative controls with secondary antibody alone were included in all experiments.

RNA extraction and real-time quantitative Polymerase Chain Reaction (PCR). MCF-7 cells were treated with LXR agonist in a 6-well plate, as previously described. Total RNA was isolated by the TriZol Reagent (Invitrogen, Cergy Pontoise, France), following the manufacturer's instructions. The mRNA $(1 \mu \mathrm{g})$ was then reverse-transcribed into cDNA using iScript ${ }^{\mathrm{TM}}$ Reverse Transcription Supermix, according to the manufacturer's instructions (Invitrogen, Cergy Pontoise, France). An initial priming step for $5 \mathrm{~min}$ at $25^{\circ} \mathrm{C}$ was followed by reserve transcription phase of $30 \mathrm{~min}$ at $42^{\circ} \mathrm{C}$ and completed by RT inactivation step of $5 \mathrm{~min}$ at $85^{\circ} \mathrm{C}$. Quantitative PCR was performed on a MyiQ2 Real-Time PCR Detection System (Bio-Rad, Marnes-la-Coquette, France) using $\mathrm{iQ}^{\mathrm{TM}}$ SYBR Green Supermix. PCR was carried out for 45 cycles of $95^{\circ} \mathrm{C}$ for $30 \mathrm{~s}$ and $60^{\circ} \mathrm{C}$ for $30 \mathrm{~s}$. FLOT2 and DHHC5 relative expressions were standardized to the reference gene $18 \mathrm{~S}$ expression, using the $\Delta \Delta \mathrm{CT}$ method. The sequences of the primers used are shown in Table I.

Data analysis. Results were confirmed in triplicates and values correspond to the mean from at least three independent experiments to verify results. The Student's $t$-test was used, and $p$-values $<0.05$ were considered significant

\section{Results}

T0901317 alters lipid rafts. We first showed by western blotting that the membrane fraction of MCF-7 cells is enriched in FLOT2. In fact, western blot analysis of plasma membrane subcellular fractions showed the presence of FLOT2 in the lipid raft fraction and a very low presence in non-lipid raft fractions of MCF-7 (Figure 1). Then we observed that T0901317 treatment of MCF-7 cells led to a decrease in the expression of FLOT2 in the whole lysates (Figure 2A) but also in the fraction corresponding to the plasma membrane (Figure 2B). Similarly, we showed that T0901317 decreased the expression of the DHHC5 enzyme which co-localizes with FLOT2 in the cell membrane (Figure 3 ).

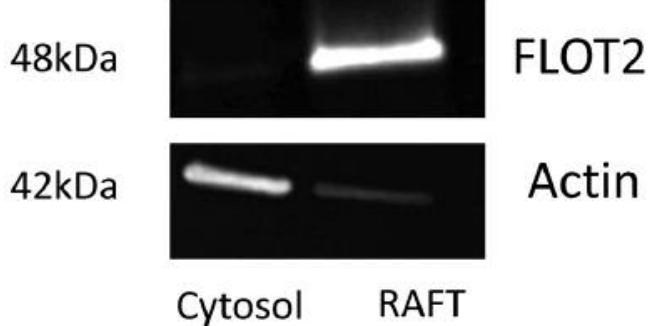

Figure 1. Expression of flotillin-2 (FLOT2) in lipid raft and non-lipid raft microdomains of the plasma membrane of MCF-7 cells. Cells were harvested and extracted with Triton X-100 as described in materials and methods to isolate the insoluble lipid rafts (RAFT) and soluble non-lipid rafts (CYTOSOL). These fractions were then subjected to western blot analysis for FLOT2 and actin expression. One representative experiment of three performed is shown.

T0901317 regulates the gene expression of FLOT2 and DHHC5. We then examined the effect of the LXR ligand on the transcription of FLOT2 and DHHC5. We thus performed a qPCR analysis. The results are presented in Figure 4 and showed a significant reduction in the mRNA level of FLOT2 in a dose- and time-dependent manner $(10 \mu \mathrm{M}$ for $24 \mathrm{~h}$ and $48 \mathrm{~h}(40 \%$ and $25 \%)$ and $20 \mu \mathrm{M}$ for $24 \mathrm{~h}$ and $48 \mathrm{~h}(50 \%$ and $60 \%)$ ) (Figure 4A). Similarly, we observed a significant reduction in the mRNA level of ZDHHC5 in a dose-and timedependent manner (10 $\mu \mathrm{M}$ for $24 \mathrm{~h}$ and $48 \mathrm{~h}(50 \%$ and $40 \%)$ and $20 \mu \mathrm{M}$ for $24 \mathrm{~h}$ and $48 \mathrm{~h}(50 \%$ and $70 \%)$ ) (Figure $4 \mathrm{~B})$.

TO901317 inhibits growth of MCF-7 breast cancer cells and alter Akt-survival pathway. In view of our results, we aimed to study the effect of LXR on the phosphorylation status of Akt, a cell survival marker associated with lipid rafts.

As shown in Figure 5, the LXR agonist reduced MCF-7 cell viability in a dose- and time- dependent manner (40, 60 and $90 \%$ at $48 \mathrm{~h}, 72 \mathrm{~h}$ and $96 \mathrm{~h}$ respectively). We next investigated the effect of T0901317 on the Akt survival pathway. Flow cytometry analysis of MCF-7 cells treated with $20 \mu \mathrm{M}$ of T0901317 (48 h) showed a marked inhibition of phospho-Akt compared to untreated control cells (Figure 6A). Means of three independent experiments confirmed these results and showed a slight inhibition of expression of phospho-Akt at 10 $\mu \mathrm{M}$ (non-significant) and about $60 \%$ inhibition by $20 \mu \mathrm{M}$ compared to untreated control cells (Figure 6B). These results were similar with those obtained with Wortmanin treated cells used as a positive control (data not shown). Immunofluorescence analysis on $\mathrm{MCF}-7$ cells was then performed. Cells were fixed, permeabilised and stained with anti-phospho-Akt (Thr-308) mAb. As shown in Figure 6C, phospho-Akt was largely translocated to the plasma membrane of untreated cells (arrows in the control left panel). In contrast, treatment of MCF-7 cells with the LXR agonist reduced cell 


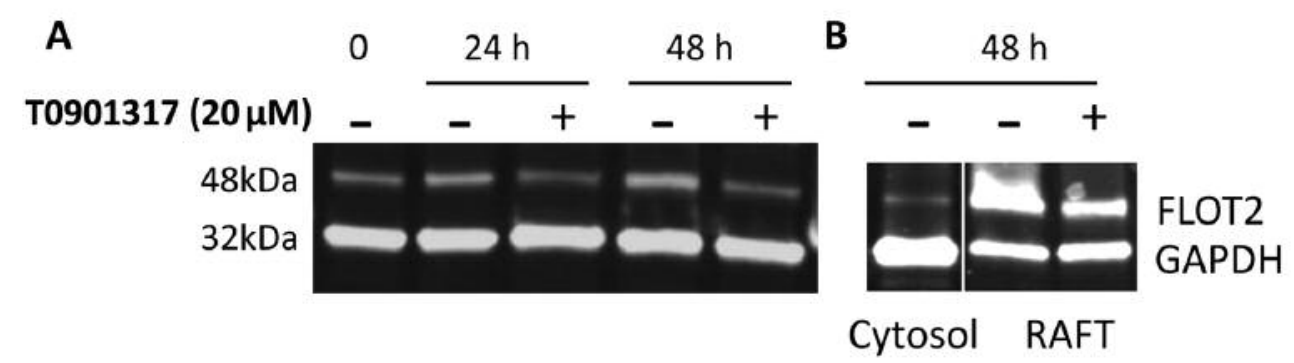

Figure 2. Expression of FLOT2 protein in plasma membrane rafts and whole-cell lysates of MCF-7 cells after treatment with Liver X Receptor (LXR) agonist T0901317. Cells were treated or not for 24 or $48 \mathrm{~h}$ with T0901317 at $20 \mu \mathrm{M}$. Total cells lysis (Whole cell extract) or Triton X-100 extraction were performed as described in the materials and methods section, to obtain soluble non-lipid rafts (CYTOSOL) or insoluble lipid rafts fraction (RAFT). Western blotting analysis for FLOT2 was then performed on whole-cell lysates $(A)$ and on Triton X-100 extraction samples (B).

surface expression of phospho-Akt (right panel). Finally, we tested the effect of T0901317 on Akt total protein level and we showed that T0901317 treatment of MCF-7 cells did not alter Akt total protein expression (Figure 6D).

\section{Discussion}

Since our laboratory had demonstrated an interesting antiproliferative effect of LXR agonist on MCF-7 cells (21) (Figure 5), we questioned whether this effect was related to lipid rafts alteration. Our hypothesis was that by accelerating membrane cholesterol efflux, via the increase of expression of ABCG1 previously highlighted by our team (21), LXR agonist T0901317 could disorganize the lipid rafts signaling platform particularly active in tumor cells. This effect was indeed demonstrated in an in vitro model of prostate cancer (14). However, the mechanism by which LXR agonist disorganizes lipid rafts is not known. For this, we investigated the effect of treatment with T0901317 on the expression of the marker of lipid rafts FLOT2 which is overexpressed in several tumor cells including breast cancer (27).

Our results confirmed our hypothesis and proved that T0901317 induces an alteration of the MCF-7 lipid rafts attested by the decreased expression of FLOT2 at the protein level in lipid rafts. Surprisingly, we also found that T0901317 decreased FLOT2 expression at the mRNA level showing that LXR stimulation can regulate the transcription of this lipid raft marker. We thus focused on the enzyme which palmitoylates FLOT2, DHHC5, and our data clearly demonstrated that expression of DHHC5 was decreased after LXR agonist treatment at both mRNA and protein level. Moreover, because the integrity of lipid rafts is associated with cell survival of tumor cells (28) including mammary tumor cells (24) we further studied the effect of LXR on the phosphorylation status of Akt, a cell survival marker associated with lipid rafts. Our results showed a

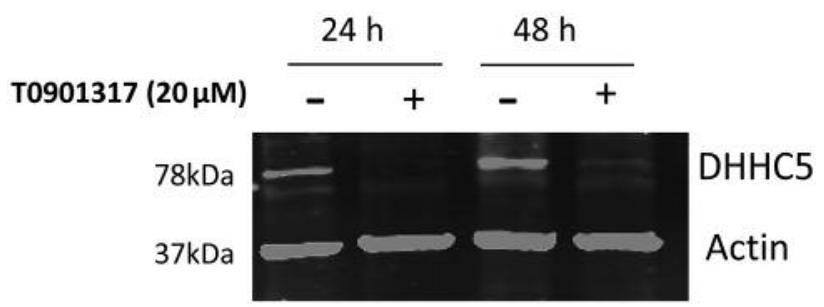

Figure 3. Expression of DHHC5 protein after treatment of MCF7 with LXR agonist T0901317. Cells were treated with T0901317 for $24 \mathrm{~h}$ and $48 \mathrm{~h}$ at $20 \mu \mathrm{M}$. After total cell lysis, study of expression of DHHC5 was analyzed by western blot.

significant decrease in the expression of the phosphorylated kinase Akt after T0901317 treatment attested by FACS and Immunofluorescence microscopy analysis without alteration of total Akt protein level (Figure 6).

The major finding of our work is the role of LXR as a modulator of lipid raft signaling in breast cancer cells. Our results clearly showed that LXR agonist can disrupt lipid rafts in breast cancer cells by accelerating cholesterol efflux but also by regulating the transcription of key markers of rafts such as FLOT2 and its acylation partner, DHHC5. This lipid raft disruption can thus explain the antiproliferative effect observed in MCF-7 cells. Furthermore, alteration of lipid rafts integrity by LXR agonist decreased the levels of Akt bound to the plasma membrane and then disrupted its phosphorylation, without altering cytosolic Akt-total protein expression. These results are in agreement with those obtained in prostate cancer cells (14).

Several perspectives can be considered. Indeed, our data showed for the first time that LXR agonist treatment can regulate DHHC5, an enzyme involved in protein palmitoylation. Recent experiments highlighted the critical role of cellular post-translational modifications like acylation 
A

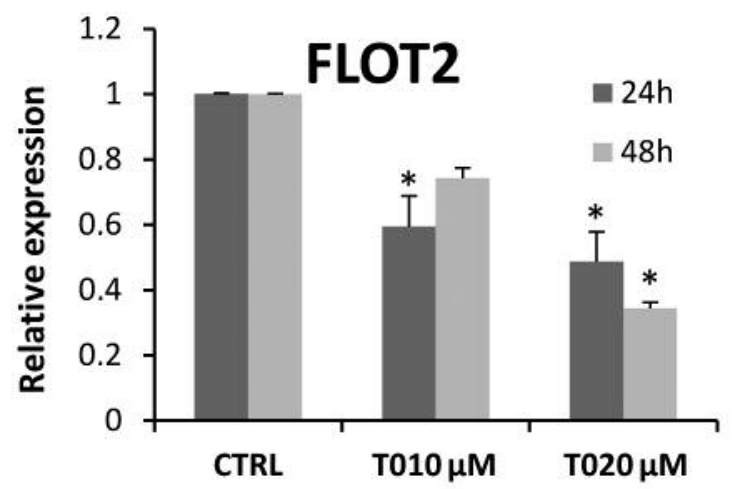

B

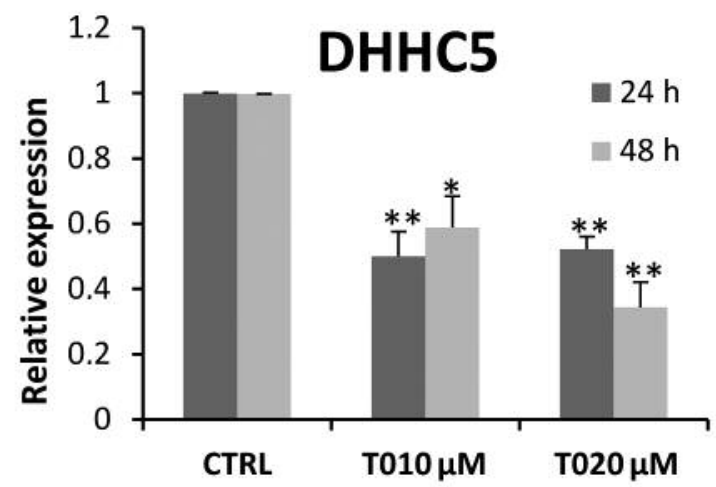

Figure 4. Effect of T0901317 on FLOT2 and ZDHHC5 genes expression. Cells were treated for $24 \mathrm{~h}$ or $48 \mathrm{~h}$ with T0901317 at 10 and $20 \mu \mathrm{M}$ and then harvested for qPCR analysis as described in the Materials and Methods. Data are means $\pm S D$ of three independents experiments.

especially in cancer (29). Specifically, it was shown that interfering with NRAS post-translational palmitoylation/ depalmitoylation cycle could disturb proper NRAS localization, and therefore decrease cell proliferation and downstream signaling (30-32). Thus, our data open new fields in the Pharmacology of cancer and targeting acylation enzymes such as DHHC family could be of particular interest.

Moreover, it seems interesting to consider the mechanism underlying the LXR-ligand dependent downregulation of FLOT2 and DHHC5 by LXR. LXR agonist dependent gene down-regulation (transrepression) has been documented in inflammatory processes where the expression of selective inflammatory genes is under control of transcription factors that can be inhibited by LXR. Indeed, transrepression is considered to involve LXR interaction with additional proteins bound to promoter regions such as members of the small ubiquitin-like modifier (SUMO) family, rather than direct interaction with DNA $(33,34)$. Regarding our data, it will be interesting to investigate the mechanism by which LXR ligand induces FLOT2 and DHHC5 gene down-regulation.

Finally, the effect of LXR agonist activity on other signaling pathways linked to lipid rafts in cancer cells should also be studied. We can cite membrane receptors associated to lipid rafts like EGFR but also membrane associated proteins whose interaction with lipid rafts is a prerequisite for their activation (by phosphorylation or acylation) such as Ras GTPase, c-Jun N-Terminal Kinase (JNK) and Src family kinases $(35,36)$.

In conclusion, in this study we showed that LXR stimulation by down-regulating FLOT2 and DHHC5 gene expression can target lipid rafts integrity but can also regulate post-translational modifications of proteins such as

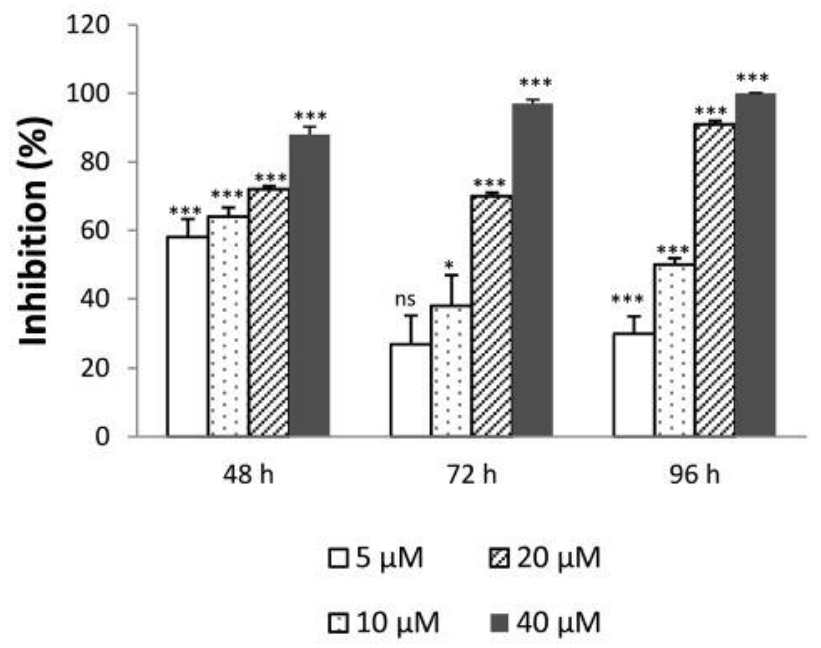

Figure 5. Effect of T0901317 on proliferation of MCF-7 cells. MCF-7 cells were treated with increased concentration of LXR agonist T0901317 during 48, 72 and 96 h. Cells viability was determined by MTT assay. Each point represents the mean $\pm S D$ of three different experiments. ${ }^{* *} p<0.001, * * p<0.01, * p<0.05$ versus untreated cells, using Student's t-test.

palmitoylation. Finally, our experiments have described new gene targets for LXR in breast cancer cells model and thus open new fields in the anticancer research.

\section{Acknowledgements}

The Authors would like to thank I. Grit and C. Bonnet (UMR 1280 Physiologie des Adaptations Nutritionnelles, INRA, Nantes, France) for their help with the immunofluorescence procedure and microscopic analysis. 
A

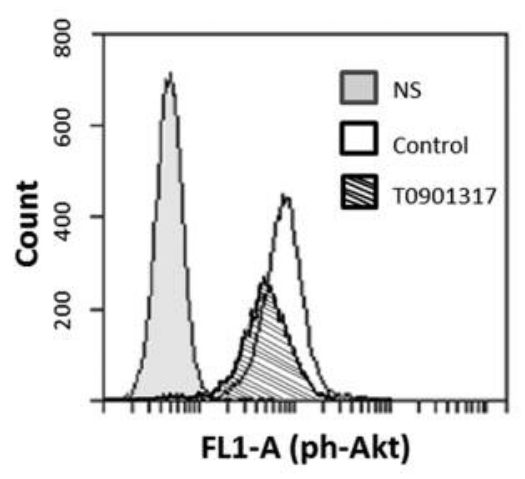

B

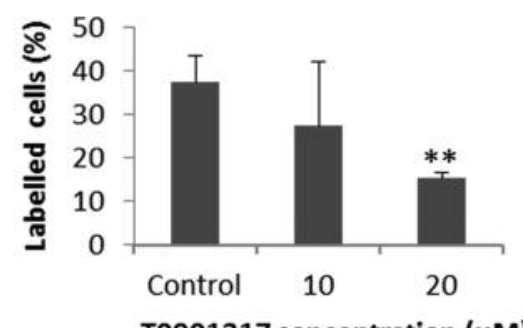

T0901317 concentration ( $\mu \mathrm{M})$

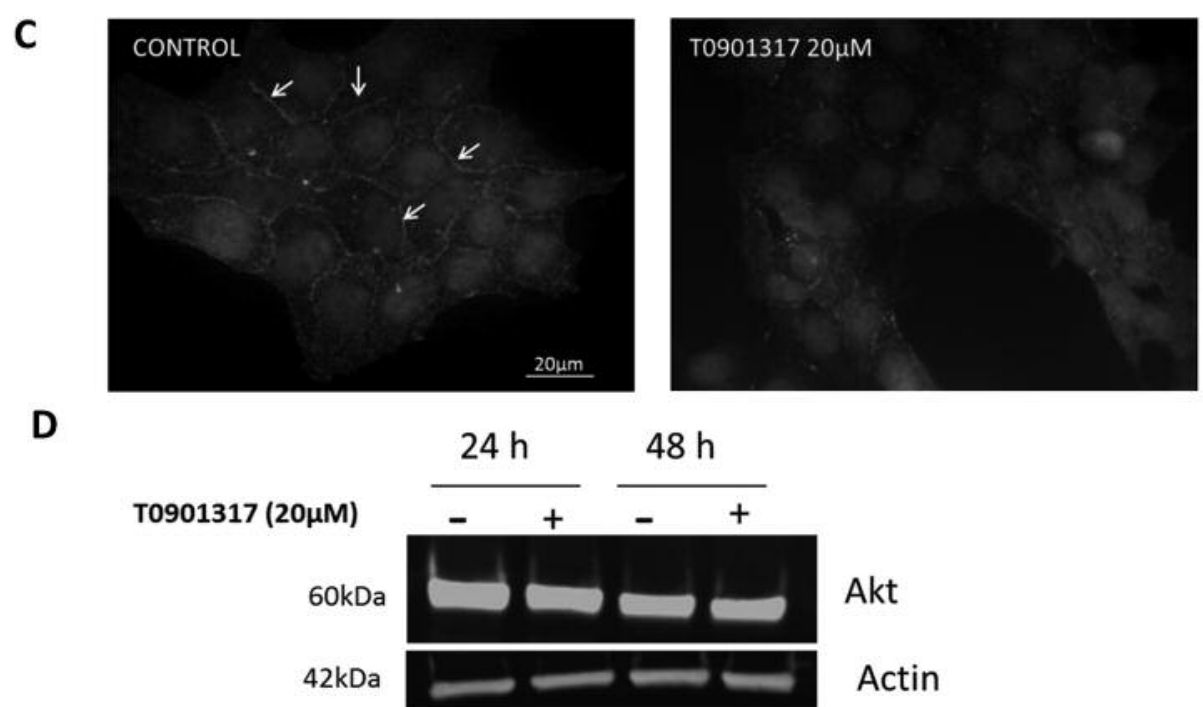

Figure 6. Effect of T0901317 on the phosphorylation status of Akt in MCF-7 cells. Analysis of phosphorylation of Akt by flow cytometry after $48 \mathrm{~h}$ of treatment with $20 \mu \mathrm{M}$ of T0901317. Cells were dyed with phospho-Akt primary antibody followed by anti-rabbit mAb dying coupled to Alexa 488. One representative experiment is presented in $(A)$ and means of three experiments are presented in $(B) . * * p<0.01$ versus untreated control cells. (C) Immunofluorescence microscopy analysis of phospho-Akt (green) in MCF-7 cells treated or not with T01901317 at $20 \mu \mathrm{M}$ for 48 h. Nuclei are stained with blue dye (DAPI). Arrows point to the localization of phospho-Akt at plasma membrane. (D) Western blotting analysis for total Akt protein on whole cell extracts.

\section{References}

1 Jemal A, Bray F, Center MM, Ferlay J, Ward E and Forman D: Global cancer statistics. CA Cancer J Clin 61(2): 69-90, 2011.

2 Gao X and Zhang J: Spatiotemporal analysis of differential Akt regulation in plasma membrane microdomains. Mol Biol Cell 19(10): 4366-4373, 2008.

3 Lasserre R, Guo X-J, Conchonaud F, Hamon Y, Hawchar O, Bernard A-M, Soudja SMH, Lenne P-F, Rigneault H, Olive D, Bismuth G, Nunes JA, Payrastre B, Marguet D and He H-T: Raft nanodomains contribute to Akt/PKB plasma membrane recruitment and activation. Nat Chem Biol 4(9): 538-547, 2008.

4 Rocks O, Peyker A, Kahms M, Verveer PJ, Koerner C, Lumbierres M, Kyhlmann J, Waldmann H, Wittinghofer A and Bastiaens PIH:
An acylation cycle regulates localization and activity of palmitoylated Ras isoforms. Science 307(5716): 1746-1752, 2005.

5 Levental I, Lingwood D, Grzybek M, Coskun U and Simons K: Palmitoylation regulates raft affinity for the majority of integral raft proteins. Proc Natl Acad Sci USA 107(51): 22050-22054, 2010.

6 Li Y, Martin BR, Cravatt BF and Hofmann SL: DHHC5 protein palmitoylates flotillin-2 and is rapidly degraded on induction of neuronal differentiation in cultured cells. J Biol Chem 287(1): 523-530, 2012.

7 Ohno Y, Kihara A, Sano T and Igarashi Y: Intracellular localization and tissue-specific distribution of human and yeast DHHC cysteine-rich domain-containing proteins. Biochim Biophys Acta 1761(4): 474-483, 2006. 
8 Bodin S, Planchon D, Rios Morris E, Comunale F and GauthierRouvière C: Flotillins in intercellular adhesion - from cellular physiology to human diseases. J Cell Sci 127(Pt 24): 5139-5147, 2014.

9 Ge L, Qi W, Wang L-J, Miao H-H, Qu Y-X, Li B-L and Song BL: Flotillins play an essential role in Niemann-Pick C1-like 1mediated cholesterol uptake. Proc Natl Acad Sci USA 108(2): 551-556, 2011.

10 Sano O, Ito S, Kato R, Shimizu Y, Kobayashi A, Kimura Y, Kioka N, Hanada K, Ueda K and Matsuo M: ABCA1, ABCG1, and $\mathrm{ABCG} 4$ are distributed to distinct membrane meso-domains and disturb detergent-resistant domains on the plasma membrane. PloS One 9(10): e109886, 2014.

11 Hong $\mathrm{C}$ and Tontonoz P: Liver X receptors in lipid metabolism: opportunities for drug discovery. Nat Rev Drug Discov 13(6): 433-444, 2014.

12 Chuu C, Hiipakka RA, Kokontis JM, Fukuchi J and Chen R-Y, Liao S: Inhibition of tumor growth and progression of LNCaP prostate cancer cells in athymic mice by androgen and liver $\mathrm{X}$ receptor agonist. Cancer Res 66(13): 6482-6486, 2006.

13 Fukuchi J, Kokontis JM, Hiipakka RA, Chuu C-P and Liao S: Antiproliferative effect of liver $\mathrm{X}$ receptor agonists on $\mathrm{LNCaP}$ human prostate cancer cells. Cancer Res 64(21): 7686-7689, 2004

14 Pommier AJC, Alves G, Viennois E, Bernard S, Communal Y, Sion B, Marceau G, Damon C, Mouzat K, Caira F, Baron S and Lobaccaro JMA: Liver X Receptor activation downregulates AKT survival signaling in lipid rafts and induces apoptosis of prostate cancer cells. Oncogene 29(18): 2712-2723, 2010.

15 Rough JJ, Monroy MA, Yerrum S and Daly JM: Antiproliferative effect of LXR agonist T0901317 in ovarian carcinoma cells. J Ovarian Res 3: 13, 2010.

16 Scoles DR, Xu X, Wang H, Tran H, Taylor-Harding B, Li A and Karlan BY: Liver X receptor agonist inhibits proliferation of ovarian carcinoma cells stimulated by oxidized low density lipoprotein. Gynecol Oncol 116(1): 109-116, 2010.

17 Lo Sasso G, Bovenga F, Murzilli S, Salvatore L, Di Tullio G, Martelli N, D’Orazio A, Rainaldi S, Vacca M, Mangia A, Palasciano $\mathrm{G}$ and Moschetta A: Liver X receptors inhibit proliferation of human colorectal cancer cells and growth of intestinal tumors in mice. Gastroenterology 144(7): 1497-1507, 2013

18 Vedin L-L, Gustafsson J-Å and Steffensen KR: The oxysterol receptors $\mathrm{LXR} \alpha$ and LXR $\beta$ suppress proliferation in the colon. Mol Carcinog 52(11): 835-844, 2013.

19 Chuu C-P and Lin H-P: Antiproliferative effect of LXR agonists T0901317 and 22(R)-hydroxycholesterol on multiple human cancer cell lines. Anticancer Res 30(9): 3643-3648, 2010.

20 Vedin L-L, Lewandowski SA, Parini P, Gustafsson J-A and Steffensen KR: The oxysterol receptor LXR inhibits proliferation of human breast cancer cells. Carcinogenesis 30(4): 575-579, 2009.

21 El Roz A, Bard J-M, Huvelin J-M and Nazih H: LXR agonists and ABCG1-dependent cholesterol efflux in MCF-7 breast cancer cells: relation to proliferation and apoptosis. Anticancer Res 32(7): 3007-3013, 2012.

22 El Roz A, Bard JM, Huvelin JM and Nazih H: The antiproliferative and pro-apoptotic effects of the trans9, trans 11 conjugated linoleic acid isomer on MCF-7 breast cancer cells are associated with LXR activation. Prostaglandins Leukot Essent Fatty Acids 88(4): 265-272, 2013.
23 Li YC, Park MJ, Ye S-K, Kim C-W and Kim Y-N: Elevated levels of cholesterol-rich lipid rafts in cancer cells are correlated with apoptosis sensitivity induced by cholesterol-depleting agents. Am J Pathol 168(4): 1107-1118, 2006.

24 Badana A, Chintala M, Varikuti G, Pudi N, Kumari S, Kappala VR and Malla RR: Lipid raft integrity is required for survival of triple negative breast cancer cells. J Breast Cancer 19(4): 372-384, 2016.

25 Raghu H, Sodadasu PK, Malla RR, Gondi CS, Estes N and Rao JS: Localization of uPAR and MMP-9 in lipid rafts is critical for migration, invasion and angiogenesis in human breast cancer cells. BMC Cancer 10: 647, 2010.

26 Alawin OA, Ahmed RA, Ibrahim BA, Briski KP and Sylvester PW: Antiproliferative effects of $\gamma$-tocotrienol are associated with lipid raft disruption in HER2-positive human breast cancer cells. J Nutr Biochem 27: 266-277, 2016.

27 Pust S, Klokk TI, Musa N, Jenstad M, Risberg B, Erikstein B, Tcatchoff L, Liestol K, Danielsen HE, van Deurs B and Sandvig $\mathrm{K}$ : Flotillins as regulators of ErbB2 levels in breast cancer. Oncogene 32(29): 3443-3451, 2013.

28 Staubach S and Hanisch F-G: Lipid rafts: signaling and sorting platforms of cells and their roles in cancer. Expert Rev Proteomics 8(2): 263-277, 2011.

29 Yeste-Velasco M, Linder ME and Lu Y-J: Protein S-palmitoylation and cancer. Biochim Biophys Acta 1856(1): 107-120, 2015.

30 Dekker FJ and Hedberg C: Small molecule inhibition of protein depalmitoylation as a new approach towards downregulation of oncogenic Ras signalling. Bioorg Med Chem 19(4): 1376-1380, 2011.

31 Vujic I, Sanlorenzo M, Esteve-Puig R, Vujic M, Kwong A, Tsumura A, Murphy R, Moy A, Posch C, Monshi B, Rappersberger K and Ortiz-Urda S: Acyl protein thioesterase 1 and 2 (APT-1, APT-2) inhibitors palmostatin B, ML348 and ML349 have different effects on NRAS mutant melanoma cells. Oncotarget 7(6): 7297-7306, 2016.

$32 \mathrm{Xu} \mathrm{J}$, Hedberg C, Dekker FJ, Li Q, Haigis KM, Hwang E, Waldmann $\mathrm{H}$ and Shannon K: Inhibiting the palmitoylation/ depalmitoylation cycle selectively reduces the growth of hematopoietic cells expressing oncogenic Nras. Blood 119(4): 1032-1035, 2012.

33 Glass CK and Ogawa S: Combinatorial roles of nuclear receptors in inflammation and immunity. Nat Rev Immunol 6(1): 44-55, 2006.

34 Pascual-García $\mathrm{M}$ and Valledor AF: Biological roles of liver X receptors in immune cells. Arch Immunol Ther Exp (Warsz) 60(4): 235-249, 2012.

35 George KS and Wu S: Lipid raft: A floating island of death or survival. Toxicol Appl Pharmacol 259(3): 311-319, 2012.

36 Hryniewicz-Jankowska A, Augoff K, Biernatowska A, Podkalicka $\mathrm{J}$ and Sikorski AF: Membrane rafts as a novel target in cancer therapy. Biochim Biophys Acta 1845(2): 155-165, 2014.
Received June 2, 2017

Revised June 19, 2017

Accepted June 20, 2017 